\title{
Is Vaginal Hysterectomy Safe for an Enlarged Uterus?
}

\author{
Pinar Yalcin Bahat ${ }^{1}$, Sibel Gülova ${ }^{2}$, Bahar Yuksel Ozgor ${ }^{3}$, Kubra Cakmak ${ }^{4}$ \\ 1. Obstetrics and Gynecology, Kanuni Sultan Süleyman Training and Research Hospital, Istanbul, TUR 2. Obstetrics \\ and Gynecology, Sisli Hamidiye Etfal Training and Research Hospital, Istanbul, TUR 3. Obstetrics and Gynecology, \\ Esenler Maternity and Children's Hospital, Istanbul, TUR 4. Obstetrics and Gynecology, Esenler Maternity and \\ Children's Hospital, Istanbul, TUR
}

Corresponding author: Pinar Yalcin Bahat, dr_pinaryalcin@hotmail.com

\section{Abstract \\ Objective}

The purpose of this study was to compare the surgical outcomes between two sets of women undergoing vaginal hysterectomy $(\mathrm{VH})$ for benign gynecological conditions: those with moderately enlarged ( $\geqslant 12$ weeks') uteruses and those with normal-sized uteruses.

\section{Materials and Methods}

The medical records of 84 women who underwent vaginal hysterectomies for benign gynecological conditions at Şişli Hamidiye Etfal Training and Research Hospital, Istanbul, Turkey between 2013 and 2015 were reviewed. Age, uterine sizes, indications, duration of hospitalization, operation time, hematocrit (HCT) levels, and complications were analyzed.

\section{Results}

The most common indications for $\mathrm{VH}$ were uterine descensus. However, most women had presented with more than one indication. The mean age of the patients who underwent VH was 56.12. The maximum volume of the uterus was found to be $1244.74 \mathrm{ml}$, and the smallest volume was found to be $18.83 \mathrm{ml}$. The mean volume of the uterus was found as $122.6629 \mathrm{ml}$. The mean duration of operation was 159.70 minutes, whereas the mean duration of hospital stay was 3.79 days. The mean preoperative HCT and hemoglobin $(\mathrm{Hgb})$ values were $37.098( \pm 3.64) \mathrm{gr} / \mathrm{dl}$ and $12.365( \pm 1.35) \mathrm{gr} / \mathrm{dl}$ respectively. Postoperative HCT and $\mathrm{Hgb}$ values were $31.363( \pm 3.94) \mathrm{gr} / \mathrm{dl}$ and $10.52( \pm 1.38)$ respectively.

\section{Conclusion}

VH is usually a simple procedure with low morbidity. It is important to choose the appropriate patient when deciding on the operation. In addition, having experienced surgeons in the field of VH increases the success of surgery.

Received 12/17/2019

Review began 01/02/2020 Review ended 01/28/2020 Published 01/30/2020

\section{๑) Copyright 2020}

Yalcin Bahat et al. This is an open access article distributed under the terms of the Creative Commons Attribution License CC-BY 3.0., which permits unrestricted use, distribution, and reproduction in any medium, provided the original author and source are credited.
Categories: Obstetrics/Gynecology, Urology, Quality Improvement

Keywords: vaginal hysterectomy, enlarged uterus, uterine size

\section{Introduction}

Hysterectomy, performed for various indications, is the most frequent among major gynecological surgeries [1]. There are three types of hysterectomy procedures: abdominal, vaginal, and laparoscopic. Vaginal hysterectomy $(\mathrm{VH})$ has advantages in aesthetics and recovery time compared to the abdominal approach [2]. However, VH feasibility is limited by uterine size and concomitant lesions within the abdominal cavity. Also, the range of indications for $\mathrm{VH}$ may vary greatly depending on the level of experience of the surgeon [3]. When VH is not indicated, abdominal hysterectomy is preferred; yet physicians may have different approaches to the same clinical circumstances, depending on training and background [4-6]. The purpose of this study is to analyze the characteristics of patients who have undergone $\mathrm{VH}$.

\section{Materials And Methods}

A retrospective chart review was performed for 84 patients who underwent VH between 2013 and 2015 at Şişli Hamidiye Etfal Training and Research Hospital, Istanbul, Turkey. Age, uterine size, indication, duration of hospitalization, operation time, hematocrit (HCT) level, and complications were analyzed. Exclusion criteria were a uterine size larger than 10 gestational weeks' size and one or more of the following conditions: prior pelvic surgery, a history of the pelvic inflammatory disease, moderate or severe endometriosis, accompanying adnexal masses, indication for adnexectomy, and nulliparity without uterine descent. All patients except those with a penicillin allergy received prophylactic antibiotic treatment (cefazolin $2 \mathrm{~g}$, intravenous) at the beginning of the operation. All patients received prophylactic 


\section{Cureus}

anticoagulant therapy with low molecular weight heparin 12 hours after the operation. All operations were performed with patients under general anesthesia.

In this retrospective cohort study, IBM SPSS Statistics for Windows, Version 23.0 (IBM, Armonk, NY) was used for statistical analysis. The suitability of the quantitative data for normal distribution, according to uterine groups, was examined by the Kolmogorov-Smirnov test. Since the data did not fit a normal distribution, the comparisons were examined by the Mann-Whitney U test. The Wilcoxon test was used for pre- and post-comparison of hemoglobin ( $\mathrm{Hgb}$ ) and HCT values for the groups. Categorical data were analyzed by the chi-square test. A p-value of $<.05$ was considered statistically significant.

Uterine volume was calculated using the ellipsoid formula, as follows: longitudinal length $(\mathrm{cm}) \mathrm{x}$ transverse length $(\mathrm{cm}) \mathrm{x}$ anteroposterior length $(\mathrm{cm}) \mathrm{x} 0.523$ (the number 0.523 corresponds to $\Pi / 6$ ) $[7,8]$. Group 1 was defined as those having a uterine volume of $\leqslant 98 \mathrm{ml}$ while those with a volume of $>98 \mathrm{ml}$ were placed in Group 2.

\section{Results}

Fifty patients had a uterine volume of $\leqslant 98 \mathrm{ml}$, and 34 patients had uterine volume $>98 \mathrm{ml}$. The indications for $\mathrm{VH}$ are listed in Table 1. The most common indication for VH was uterine descensus. However, most of the women presented with more than one indication. The demographic data of the patients are listed in Table 2. The mean age of the patients who underwent VH was 55 years (range: $40-80$ years). Prophylactic bilateral salpingo-oophorectomy was performed for 43 patients. Anterior colporrhaphy was also done for 44 patients; posterior colporrhaphy was added to the operations of 39 patients, and transobturator tape was additionally added for seven patients, while sacrospinous fixation was performed on 23 patients receiving VH. The mean uterine volume was $75.1 \mathrm{ml}$ (range: $18.8-1244.7 \mathrm{ml}$ ).

\begin{tabular}{|ll|}
\hline Diagnosis* & Number of patients** $(\%)$ \\
\hline Uterine descensus & $52(61)$ \\
Leiomyoma & $19(22)$ \\
Cystocele & $20(23)$ \\
Rectocele & $8(9)$ \\
Urinary incontinence & $12(14)$ \\
Dysfunctional uterine bleeding & $3(3)$ \\
\hline
\end{tabular}

\section{TABLE 1: Preoperative diagnosis}

*Most patients presented with more than one indication

**Total number of patients: 84 


\section{Cureus}

\begin{tabular}{|c|c|c|c|c|}
\hline Characteristics, mean & Group $1, n=50$ & Group 2, $n=34$ & Total, $\mathrm{n}=84$ & P-value** \\
\hline Age, years & $59.5(40-80)^{\star}$ & $50(41-70)^{\star}$ & $55(40-80)^{\star}$ & .000 \\
\hline Gravida, n & $6(1-14)^{\star}$ & $4(1-10)^{*}$ & $5(1-14)^{*}$ & .015 \\
\hline Parity, $n$ & $4(1-13)^{\star}$ & $3(1-9)^{\star}$ & $3.5(1-13)^{\star}$ & .016 \\
\hline Abortion, $\mathrm{n}$ & $0(0-5)^{\star}$ & $0(0-7)^{\star}$ & $0(0-7)^{\star}$ & 467 \\
\hline Curettage, $n$ & 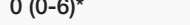 & 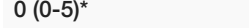 & $0(0-6)^{x}$ & .300 \\
\hline Operation duration, minutes & $150(50-300)^{*}$ & $175(60-300)^{\star}$ & $150(50-300)^{\star x}$ & 291 \\
\hline Hospitalization time, days & $3.5(1-12)^{\star}$ & $4(2-8)^{\star}$ & $4(1-12)^{\star}$ & .259 \\
\hline Longitudinal length, $\mathrm{cm}$ & 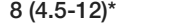 & $10(7.5-17)^{\star}$ & $9(4.5-17)^{\star}$ & .000 \\
\hline Transverse length, cm & $4(3-6.5)^{\star}$ & $6(5-14)^{\star}$ & $5(3-14)^{*}$ & .000 \\
\hline Anteroposterior length, cm & $2.5(1.5-5)^{\star}$ & $5(4-10)^{\star}$ & $3.5(1.5-10)^{\star}$ & .000 \\
\hline Volume, ml & $47.3(18.8-95.4)^{\star}$ & $162.4(100.4-1244.7)^{\star}$ & $75.1(18.8-1244.7)^{\star}$ & .000 \\
\hline Preoperative $\mathrm{Hgb}, \mathrm{g} / \mathrm{dl}$ & $12.7(9.2-15.3)$ & $12.2(5.8-14.2)^{\star}$ & $12.4(5.8-15.3)^{\star}$ & .016 \\
\hline Preoperative HCT, g/dl & $37.9(29.4-44)^{\star}$ & $36.2(18.8-42.4)^{\star}$ & $37.6(18.8-44)^{\star}$ & .079 \\
\hline Postoperative Hgb, g/dl & $11(6-13.7)^{\star}$ & $10.6(7.8-12.4)^{\star}$ & $10.7(6-13.7)^{\star}$ & .066 \\
\hline Postoperative HCT, g/dl & $32.4(19.2-40.1)^{\star}$ & $31.5(23.9-37.2)^{\star}$ & $32(19.2-40.1)^{*}$ & .125 \\
\hline
\end{tabular}

\section{TABLE 2: Comparison of quantitative data by groups}

${ }^{*}$ Figures in parentheses represent the range

${ }^{\star \star}$ Mann-Whitney U test

HCT: hematocrit; Hgb: hemoglobin

The mean preoperative HCT and Hgb values were $37.6 \mathrm{~g} / \mathrm{dl}$ (range: 18.8-44 g/dl) and $12.4 \mathrm{~g} / \mathrm{dl}$ (range: 5.8$15.3 \mathrm{~g} / \mathrm{dl})$, respectively; whereas postoperative HCT and $\mathrm{Hgb}$ values were $32 \mathrm{~g} / \mathrm{dl}(19.2-40.1 \mathrm{~g} / \mathrm{dl})$ and 10.7 $\mathrm{g} / \mathrm{dl}$ (range: 6-13.7 g/dl), respectively. There was no significant difference between the two groups in terms of changes in uterine volume or HCT and Hgb values (Hgb p: .066; hct p: .125). The mean duration of the operations was 150 minutes (range: 50-300 minutes), whereas the mean hospitalization time was four days (range: 1-12 days).

Menopausal status varied between the groups (p:<.001); $88 \%$ of patients in the small uterus and $23.5 \%$ in the large uterus group were menopausal. Data pertaining to smoking, diabetes mellitus, hypertension, coronary artery disease, thyroid conditions, previous abdominal surgery history, transfusion, and complications were not much different between the groups (p: >.05; Table 3). 


\section{Cureus}

\begin{tabular}{|c|c|c|c|c|}
\hline Characteristics, mean & Group 1, n (\%), total number = 50 & Group 2, n (\%), total number = 34 & Total $n(\%)$, total number $=84$ & P-value ${ }^{*}$ \\
\hline \multicolumn{5}{|l|}{ Menopause } \\
\hline No & $6(12)$ & $26(76.5)$ & $32(38.1)$ & \\
\hline Yes & $44(88)$ & $8(23.5)$ & $52(61.9)$ & \\
\hline \multicolumn{5}{|l|}{ Cigarette use } \\
\hline No & 44 (88) & $30(88.2)$ & $74(88.1)$ & \multirow{2}{*}{1.000} \\
\hline Yes & $6(12)$ & $4(11.8)$ & $10(11.9)$ & \\
\hline \multicolumn{5}{|l|}{ Diabetes mellitus } \\
\hline No & $44(88)$ & $32(94.1)$ & $76(90.5)$ & \multirow{2}{*}{.464} \\
\hline Yes & $6(12)$ & $2(5.9)$ & $8(9.5)$ & \\
\hline \multicolumn{5}{|l|}{ Hypertension } \\
\hline No & $32(64)$ & $23(67.6)$ & $55(65.5)$ & \multirow{2}{*}{.911} \\
\hline Yes & $18(36)$ & $11(32.4)$ & $29(34.5)$ & \\
\hline \multicolumn{5}{|l|}{ Coronary artery disease } \\
\hline No & $48(96)$ & $29(85.3)$ & $77(91.7)$ & \multirow{2}{*}{.113} \\
\hline Yes & $2(4)$ & $5(14.7)$ & $7(8.3)$ & \\
\hline \multicolumn{5}{|l|}{ Thyroid disease } \\
\hline No & $41(82)$ & $26(76.5)$ & $67(79.8)$ & \multirow{2}{*}{.732} \\
\hline Yes & $9(18)$ & $8(23.5)$ & $17(20.2)$ & \\
\hline \multicolumn{5}{|c|}{ Previous abdominal surgery } \\
\hline No & $34(68)$ & $29(85.3)$ & $63(75)$ & \multirow{2}{*}{.124} \\
\hline Yes & $16(32)$ & $5(14.7)$ & $21(25)$ & \\
\hline \multicolumn{5}{|l|}{ Transfusion } \\
\hline No & $46(92)$ & $30(88.2)$ & $76(90.5)$ & \multirow{2}{*}{.709} \\
\hline Yes & $4(8)$ & $4(11.8)$ & $8(9.5)$ & \\
\hline \multicolumn{5}{|l|}{ Complication } \\
\hline No & $48(96)$ & $34(100)$ & $82(97.6)$ & \multirow{2}{*}{.512} \\
\hline Yes & $2(4)$ & $0(0)$ & $2(2.4)$ & \\
\hline
\end{tabular}

\section{TABLE 3: Comparison of categorical data by groups}

${ }^{*}$ Chi-square test

Five women required blood transfusion postoperatively because of excessive hemorrhage. Four women needed blood transfusions before their operations because of anemia. Bladder injury occurred in two women after VH. The injury was noticed during the operation and repaired perioperatively. There were no ureter or bowel injuries, vesicovaginal fistulae, neurologic or thromboembolic complications identified during the study. Four patients underwent laparotomy due to unstoppable excessive bleeding during VH. Patients with a uterine volume of $\leqslant 98 \mathrm{ml}$ and those with a uterine volume of $>98 \mathrm{ml}$ were both evaluated for complications and transfusion. There was no difference in complication and transfusion rates between the groups (complication: p: .512; transfusion: p: .709).

\section{Discussion}

In obstetrics and gynecology, hysterectomy is the second most commonly performed surgery after the 
Cesarean section [9]. The patient's anatomy and the surgeon's experience are highly important for choosing the type of hysterectomy [10]. Despite the advantages of the VH, most surgeons hesitate to perform the procedure when faced with a large uterus, previous history of pelvic or salpingo-oophorectomy surgery, pelvic inflammatory disease, severe endometriosis, adnexal mass, or descensus in non-uterine cases.

Feroze et al. reported indications for $\mathrm{VH}$ as benign uterine diseases, a size not greater than which corresponding to a 12-gestational week uterus ( $<280 \mathrm{~g})$, uterine prolapse, small leiomyomas, cases with severe dysmenorrhea, and cases with functional uterine bleeding concomitant with uterine prolapse [10]. Subsequent studies have led to some changes in terms of indications for VH. For example, Kammerer-Doak et al. and Mazdisnian et al. reported no prominent distinction according to the size of the uterus [11,12]. Although the indications have been expanded, there are still some limitations for $\mathrm{VH}$, such as prior pelvic surgery, a history of pelvic inflammatory disease, moderate or severe endometriosis, accompanying adnexal masses, indication for adnexectomy, and nulliparity without uterine descent [9].

In a study conducted by Amy in 1997, VH was performed for 14 cases with uterine weight up to $639 \mathrm{~g}$, and they found no difference in terms of complications [13]. As Magos et al. concluded, uterine size by itself should no longer be considered as a contraindication for $\mathrm{VH}$. As reported previously, prior pelvic surgery, mild endometriosis, history of pelvic inflammatory disease, or leiomyoma should no longer be viewed as contraindications for vaginal surgery [14].

In our study, 20 patients had a history of Cesarean section, and six patients had undergone prior surgery due to various indications. However, no complications occurred. In our study, the most common indication for VH was descensus uteri, which is consistent with the literature $[15,16]$.

Prophylactic adnexectomy is much less frequent in VH due to technical issues. In a study by Wilcox et al., prophylactic oophorectomy was performed in $85 \%$ of the women who had abdominal hysterectomies, while only $18 \%$ of women had oophorectomy with $\mathrm{VH}$ [17]. In our study, 43 patients had prophylactic bilateral salpingo-oophorectomy.

In a study published in the US, the overall complication rate was $42.8 \%$ in abdominal hysterectomies and $24.5 \%$ in $\mathrm{VH}$. The risk of developing one or more complications after surgery is 1.7-times greater in abdominal hysterectomies [18]. In our study, bladder injuries occurred in two (2\%) patients during vaginal hysterectomy and four (4\%) patients during laparotomy due to excessive bleeding. Only five patients needed blood transfusion postoperatively due to blood loss.

No correlation was found between uterine volume and operation time or discharge time: 50 of the 84 patients (59.5\%) included in the study were in the small uterine group, and 34 (40.5\%) were in the large uterine group.

\section{Conclusions}

Although VH has obvious advantages compared with other techniques, a detailed examination should be performed as part of the treatment planning process. If there is a contraindication, one should not insist on it; rather, one should switch to an abdominal or laparoscopic technique. Consequently, the success rate of the operation may increase with the presence of correct indications and the availability of a sufficiently experienced surgeon.

\section{Additional Information \\ Disclosures}

Human subjects: Consent was obtained by all participants in this study. Animal subjects: All authors have confirmed that this study did not involve animal subjects or tissue. Conflicts of interest: In compliance with the ICMJE uniform disclosure form, all authors declare the following: Payment/services info: All authors have declared that no financial support was received from any organization for the submitted work. Financial relationships: All authors have declared that they have no financial relationships at present or within the previous three years with any organizations that might have an interest in the submitted work. Other relationships: All authors have declared that there are no other relationships or activities that could appear to have influenced the submitted work.

\section{References}

1. Ferrari MM, Berlanda N, Mezzopane R, Ragusa G, Cavallo M, Pardi G: Identifying the indications for laparoscopically assisted vaginal hysterectomy: a prospective, randomised comparison with abdominal hysterectomy in patients with symptomatic uterine fibroids. BJOG. 2000, 107:620-5. 10.1111/j.14710528.2000.tb13303.x

2. Richardson RE, Bournas N, Magos AL: Is laparoscopic hysterectomy a waste of time? . Lancet. 1995, 345:3641. 10.1016/s0140-6736(95)91158-8

3. Easterday CL, Grimes DA, Riggs JA: Hysterectomy in the United States. Obstet Gynecol. 1983, 62:203-12.

4. McPherson K, Wennberg JE, Hovind OB, Clifford P: Small-area variations in the use of common surgical 
procedures: an international comparison of New England, England, and Norway. N Engl J Med. 1982, 307:1310-4. 10.1056/NEJM198211183072104

5. Phipps JH, John M, Nayak S: Comparison of laparoscopically assisted vaginal hysterectomy and bilateral salpingo-oophorectomy with conventional abdominal hysterectomy and bilateral salpingo-oophorectomy. Br J Obstet Gynaecol. 1993, 100:698-700. 10.1111/j.1471-0528.1993.tb14246.x

6. Davies A, Magos AL: Indications and alternatives to hysterectomy. Baillieres Clin Obstet Gynaecol. 1997, 11:61-75. 10.1016/s0950-3552(97)80050-8

7. Casikar I, Mongelli M, Reid S, Condous G: Estimation of uterine volume: a comparison between Viewpoint and 3D ultrasound estimation in women undergoing laparoscopic hysterectomy. Australas J Ultrasound Med. 2015, 18:27-32. 10.1002/j.2205-0140.2015.tb00020.x

8. Burt E, Davies MC, Yasmin E, Cameron-Pimblett A, Mavrelos D, Talaulikar V, Conway GS: Reduced uterine volume after induction of puberty in women with hypogonadism. Clin Endocrinol (Oxf). 2019, 91:798-804. 10.1111/cen.14092

9. Kovac SR: Guidelines to determine the route of hysterectomy. Obstet Gynecol. 1995, 85:18-23. 10.1016/0029-7844(94)00318-8

10. Feroze RM: Vaginal hysterectomy and repair. Clin Obstet Gynaecol. 1978, 5:545-56.

11. Kammerer-Doak D, Mao J: Vaginal hysterectomy with and without morcellation: the University of New Mexico hospital's experience. Obstet Gynecol. 1996, 88:560-3. 10.1016/0029-7844(96)00237-2

12. Mazdisnian F, Kurzel RB, Coe S, Bosuk M, Montz F: Vaginal hysterectomy by uterine morcellation: an efficient, non-morbid procedure. Obstet Gynecol. 1995, 86:60-4. 10.1016/0029-7844(95)00086-7

13. Amy JJ: Vaginal hysterectomy. Natl Med J India. 1997, 10:126-7.

14. Magos A, Bournas N, Sinha R, Richardson RE, O’Connor H: Vaginal hysterectomy for the large uterus. Br J Obstet Gynaecol. 1996, 103:246-51. 10.1111/j.1471-0528.1996.tb09713.x

15. Carlson KJ, Nichols DH, Schiff I: Indications for hysterectomy. N Engl J Med. 1993, 328:856-60. 10.1056/NEJM199303253281207

16. van den Eeden SK, Glasser M, Mathias SD, Colwell HH, Pasta DJ, Kunz K: Quality of life, health care utilization, and costs among women undergoing hysterectomy in a managed-care setting. Am J Obstet Gynecol. 1998, 178:91-100. 10.1016/s0002-9378(98)70633-7

17. Wilcox LS, Koonin LM, Pokras R, Strauss LT, Xia Z, Peterson HB: Hysterectomy in the United States, 19881990. Obstet Gynecol. 1994, 83:549-55. 10.1097/00006250-199404000-00011

18. Shen CC, Wu M-P, Lu CH, et al.: Short- and long-term clinical results of laparoscopic-assisted vaginal hysterectomy and total abdominal hysterectomy. J Am Assoc Gynecol Laparosc. 2003, 10:49-54. 10.1016/s1074-3804(05)60234-4 